\title{
FISCALIZAÇÃO E FORMAÇÃO DAS PARTEIRAS EM SAO PAULO (1880-1920)
}

\author{
MIDWIVES TRAINNING AND CONTROL IN SAO PAULOBRAZIL (1880-1920)
}

\author{
Maria Lúcia Mott*
}

MOTT, ML. Fiscalização e formação das parteiras em São Paulo (1880-1920). Rev Esc Enf USP, v.35, n, 1, p. 46-53, mar. 2001.

\begin{abstract}
RESUMO
Este artigo faz parte de uma pesquisa mais ampla realizada em nivel de Pós-Doutuorado na Escola de Enfermagem da USP (1999-2000), intitulada "Caminhos Cruzados: os cursos para formação de parteiras e enfermeiras em São Paulo (1880-1971)" que teve por objetivo refletir sobre as atribuições de parteiras e enfermeiras obstétricas e a exclusão dessas profissionais na assistência ao parto no decorrer do século XX. O artigo se detém nos primeiros cursos para formação de parteiras e na fiscalização da profissão, apontando que no inicio do século XX, já se pode perceber uma associação entre parteiras e enfermeiras, não apenas em alguns cursos para formação profissional, como também no cotidiano de trabalho. Passa a existir a expectativa de que a parteira fosse também enfermeira.
\end{abstract}

PALAVRAS-CHAVE: História da enfermagem. Enfermagem obstétrica, Parteira.

\begin{abstract}
This paper is part of a major research, entitled "Crossed Roads: the training schools for midwives and nurses in São Paulo (1880-1971)". Its objectives is to discuss the midwives' and nurse-midwives 'roles and their exclusion in the attendance to the childbirth. This study has focused on the first training schools for midwives and the control of the profession, showing that at the beginning of the XXth century, one can already notice a close relationship between midwives and nurses, not just in the schools, but also in the daily work. It starts some expectation that midwifes become nurses too.
\end{abstract}

KEYWORDS: History of nursing. Obstetrical nursing, Midwife.

Nos anos finais do Império, a fiscalização do exercício profissional de médicos, farmacêuticos, dentistas e parteiras, no Brasil, estava a cargo da Inspetoria Geral de Higiene, que tinha representantes nas provincias. Só era permitido o exercício às parteiras que se mostrassem habilitadas por diploma conferido ou validado (no caso das estrangeiras) pelas duas faculdades de Medicina existentes no Império, a do Rio de Janeiro e da Bahia. As parteiras deveriam registrar seu diploma na Inspetoria Geral de Higiene da Corte e na Inspetoria da provincia onde fossem exercer a profissão. Em caso de mudança de província, eram obrigadas a registrarem-se novamente. $\mathrm{O}$ exercício profissional tinha restrições precisas: limitava a prestar os cuidados indispensáveis à mãe e ao recém-nascido nos partos naturais. Em caso de distócia as parteiras eram obrigadas a chamar o médico sem demora. Até que este chegasse, deveriam empregar somente os meios conhecidos para prevenir qualquer acidente que pudesse comprometer a vida da parturiente ou do feto. O Decreto 9554 (BRASIL, 1886) proibia o tratamento das moléstias de mulheres e das crianças, os anúncios de consultas ginecológicas, receitar, salvo de medica- mentos conhecidos, para prevenir acidentes graves. Tais receitas deveriam conter a declaração "urgente". Previa, também, o pagamento de multa e a suspensão da parteira em caso de falta grave.

Com o advento da República foi constituído pelo Governo Provisório, o Conselho de Saúde Pública, reorganizado o Serviço Sanitário e elaborado um novo Código Penal, que definia como crime o exercício da medicina em qualquer um dos seus ramos sem a habilitação determinada pelas leis e regulamentos. O Decreto 169 (Brasil, 1890) que reorganizou o Serviço Sanitário, estabeleceu que competia à União a fiscalização da medicina e da farmácia através da Inspetoria Geral de Higiene. Embora os demais ramos da medicina não tivessem sido contemplados no artigo n.9, a fiscalização do exercício e as atribuições das parteiras estavam previstos nos artigos 43,44 , 48, cujo conteúdo é semelhante àquele que tinha sido estabelecido pela legislação anterior.

No que se refere à fiscalização do exercício profissional, pode-se dizer que no início da República, a União centralizou as decisões, assim como ocorria no Império, cabendo aos Estados uma parcela menor

* Doutora em História pela USP. Pós-Doutora pela Escola de Enfermagem da USP. Professora de História da Enfermagem na Faculdade Adventista de Enfermagem, E.mail: cucamott@uol.com.br 
de atribuições e decisões, situação esta que começou a ser modificada já no ano seguinte, quando passaram a ser organizados os serviços sanitários nos Estados.

Em 1897, um novo decreto (n. 2548) aprovou o regulamento da Diretoria Geral de Higiene Pública que estabelecia que o governo federal se incumbiria apenas assessoriamente do serviço de fiscalização do exercício da medicina em todos os seus ramos, no que fosse inerente á capacidade legal e não estivesse providenciado por lei dos Estados e Municípios. Nos Estados e Municípios que não houvesse lei ou regulamento especial sobre o assunto, a fiscalização deveria ser exercida pela autoridade sanitária federal (BRASIL, 1897).

No Estado de São Paulo, ao longo da década de 1890, a classe médica discutiu a necessidade de regulamentar o exercício profissional de farmacêuticos, dentistas e parteiras, de organizar o Serviço Sanitário e fazer cumprir as determinações sobre a fiscalização do exercício profissional. No final de 1891, a Inspetoria de Higiene de São Paulo foi desligada da administração federal (BRASIL, 1891), em 1892 (SÃO PAULO, 1892), foi organizado o Serviço Sanitário, e, em 1893 (SÃO PAULO, 1893), foi reorganizado, sendo aprovado o regulamento, em 1896. Esse regulamento seguia de perto legislação federal no que se refere ao exercício das parteiras, ou seja só poderiam exercer "as pessoas que se mostrassem habilitadas por título conferido ou reconhecido por qualquer das Faculdades de Medicina da República dos Estados Unidos do Brasil, e tiverem seus títulos registrados na diretoria do Serviço Sanitário (SAO PAULO, 1896). Antes mesmo da aprovação da nova lei, o Serviço Sanitário já havia convocado 22 parteiras que exerciam na cidade de São Paulo, para se apresentarem à diretoria daquela repartição com os respectivos diplomas (PARTEIRAS, 1896).

Em 1898, o Boletim da Sociedade de Medicina e Cirurgia de São Paulo publicou uma representação de médicos e farmacêuticos dirigida a Emilio Ribas, então diretor do Serviço Sanitário, com o objetivo de que fossem tomadas providências contra os abusos cometidos por individuos que exerciam os diferentes ramos da medicina, sem título legalizado (REPRESENTAÇÃO, 1898) ${ }^{1}$. O Serviço Sanitário imediatamente se manifestou e publicou um edital convocando médicos, farmacêuticos, dentistas e parteiras a registrarem seus titulos naquela diretoria e intimando as pessoas que exerciam sem título legalizado a não continuarem, sob pena de serem denunciadas às autoridades policiais. Em fevereiro de 1899, foi remetida ao secretário dos Negócios do
Interior, pela diretoria do Serviço Sanitário, uma lista de profissionais que exerciam ilegalmente o oficio (SERVIÇO SANITÁRIO, 1899).

No mesmo ano de 99, o legislativo de São Paulo, contrariando o que havia regulamentando pelo Decreto 394 (SÃO PAULO,1896), aprovou o exercício profissional de parteiras e dentistas práticos, desde que se submetessem a um exame, enquanto não houvesse curso de Partos e de Odontologia na cidade. O exame passou a ser realizado pela recém-criada Escola Livre de Farmácia.

Apesar da nova lei (SÃO PAULO,1899) admitir a habilitação de parteiras práticas, exigia que as candidatas possuíssem um conhecimento teórico aprovado e reconhecido pelo saber médico. 0 exame versava sobre Anatomia da bacia e do aparelho genital da mulher, Fisiologia da prenhez, Patologia Clínica e Terapêutica Obstétrica e constava de prova escrita, oral e prática. A comissão de exame era composta pelo diretor da Maternidade de São Paulo, por três lentes da Escola Livre de Farmácia, formados em Medicina, e por um fiscal do governo. As candidatas à habilitação deveriam apresentar os seguintes documentos: certificado de nascimento e de vacinação, prova de identidade e idoneidade e pagar uma taxa exigida pela escola (ESCOLA LIVRE DE FARMÁCIA, 1900). A Escola Livre de Farmácia habilitou seis parteiras práticas, todas com sobrenome de origem italiana ${ }^{2}$.

Em 1902, foram criados, na referida Escola, os cursos de Odontologia e de Obstetrícia, que passou a ser intitulada "Escola Livre de Farmácia, Odontologia e Obstetrícia de São Paulo" (ELFOO). Os cursos foram reconhecidos em 1903 (SAO PAULO, 1903) pelo legislativo estadual, e, em 1905, pelo federal (BRASIL, 1905). As parteiras práticas habilitadas anteriormente pela escola, continuaram autorizadas a exercer a profissão.

Em 1903, uma representação da ELFOO forneceu ao Congresso um esboço de regulamento sobre o exercício profissional de farmacêuticos, dentistas e parteiras que, depois de uma série de discussões e modificações, foi aprovado cinco anos mais tarde pelo legislativo paulista, em 1908. Pelo novo regulamento só poderiam exercer a profissão de parteira no Estado: 1) as mulheres diplomadas pela ELFOO de São Paulo ou por qualquer das escolas oficiais ou equiparadas da União; 2) as parteiras diplomadas por escolas estrangeiras que tivessem sido habilitadas perante as mesmas escolas do Estado ou da União, provada a identidade da pessoa. Para exercer a profissão no Estado, a parteira era obrigada a registrar seu titulo na Diretoria do Serviço Sanitário (SÃO PAULO, 1908).

\footnotetext{
Ver também: EXERCÍCIO ILEGAL DA MEDICINA, 1898.

2 Ver: Livro rf.239, "Lista Geral dos alunos que concluíram o curso na Escola ". Arquivo da Faculdade de Odontologia da USP
} 
Os anúncios de jornais sugerem que a Lei 1143

A lei proibia às parteiras anunciar consultas e praticar ginecologia, dar receitas ou aplicar quaisquer medicamentos que não fossem aqueles aconselhados na prática da assepsia obstétrica; praticar qualquer manobra em caso de distócia, salvo quando o médico não tivesse chegado a tempo; receber parturiente ou gestante em sua residência ou em outro qualquer lugar que tivesse caráter de maternidade ou enfermaria.

Como pode-se verificar, a lei excluía as parteiras práticas habilitadas pela Escola $^{3}$ e era bastante restritivo no que se refere ao exercício profissional, cuja atuação deveria se limitar a prestar os cuidados indispensáveis às parturientes e aos recém-nascidos nos partos naturais e só excepcionalmente, na falta de médico, realizar partos laboriosos. Além de reafirmar a proibição de executar manobras, fazer operações obstétricas, receitar medicamentos e fazer consultas ginecológicas, como já tinha sido estabelecido pela legislação federal e estadual anteriormente, passou a restringir também, o local de atendimento: as parteiras não poderiam mais receber parturientes em suas casas.

Vale lembrar que nas primeiras décadas do século as consultas ginecológicas e os partos eram realizados pelas parteiras, sobretudo no domicilio da parturiente ou de pessoa de sua relação. Desde o século anterior, pelo menos nas principais cidades do Brasil, havia parteiras que faziam partos em suas próprias casas, tendo quartos especiais para parturientes. Com o passar dos anos essa forma de atendimento se ampliou e alguns estabelecimentos passaram a ser conhecidos pelo nome de casas de maternidade. Aí eram atendidas em geral mulheres que por alguma razão estavam impedidas de dar à luz junto da família, como por exemplo, as provenientes do interior, mães solteiras e as viúvas. Em São Paulo, a situação não era diferente. Em 1878, Adele Gourges - que por sinal anos mais tarde mudou-se para o Rio de Janeiro informava através das páginas do Indicador de São Paulo que tinha uma casa de maternidade na Rua Boa Vista; Ana Cantaldi, parteira diplomada pela Universidade de Nápoles e plenamente aprovada pela Faculdade de Medicina do Rio de Janeiro, "recebia parturientes em pensão", na Rua General Jardim, n. 46, na Vila Buarque, conforme atesta anúncio no jornal O Estado de São Paulo de 27/02/1899.

Apesar da importância do serviço e socorro prestados às mulheres, esses estabelecimentos eram considerados locais perniciosos, onde prostitutas davam à luz e as parteiras podiam fazer abortos, sendo por isso denunciados ao longo da segunda metade do século XIX, até serem proibidos de funcionar.
(SAO PAULO, 1908) nem sempre foi obedecida no que se refere ao acolhimento, pelas parteiras, de parturientes em suas residências, bem como ao tratamento ginecológico. As páginas do jornal $\mathbf{O}$ Estado de São Paulo são pródigas de exemplos de parteiras que infringiam a lei. Em 15/01/1909, Rosina Ferraro anunciava que era diplomada pela Régia Universidade de Gênova, aprovada pela Faculdade de Medicina do Rio de Janeiro e de Buenos Aires, especialista em doenças de senhoras e tinha consultório em sua residência, no largo São Bento, onde atendia a qualquer hora; no dia 2/12/1916 no mesmo jornal Elisa Carlini publicava um anúncio oferecendo seus serviços. A parteira afirmava que era diplomada pelas Faculdades de Medicina de Padova e do Rio de Janeiro, tinha 30 anos de prática, e que recebia pensionistas na sua nova residência, na Rua 13 de maio, n.16 A.

No que se refere às penalidades das infrações, a lei estipulava que a parteira que, por inobservância dos preceitos de assepsia obstétrica, ocasionasse doença de natureza infecciosa ao recém-nascido; ou, que por impericia e por manobras intempestivas, transformasse um parto normal em uma distócia; ou que, por inobservância dos preceitos obstétricos, determinasse lesões irreparáveis e acidentes graves que pudessem comprometer a saúde e a vida da mulher ou do feto, seria punida com suspensão do exercício profissional, multa, e penalidades previstas pelo Código Penal. A lei proibia, ainda, o exercício da profissão à parteira afetada de tuberculose ou de qualquer outra doença infecciosa, contagiosa ou "asquerosa", comprovada em exame perante a junta médica, sob pena de multa, e de suspensão do exercício por tempo indeterminado.

Na literatura médica do período, não é raro se deparar com críticas às parteiras leigas, sobretudo no que diz respeito à ignorância, à falta de conhecimentos básicos de higiene, à prática de manobras de forma incorreta e o uso inadequado de medicamentos. O alvo das criticas recaia sobre as brasileiras de origem africana, como também sobre as imigrantes, sobretudo italianas de "dez filhos e unhas sujas" (AZEVEDO JR., 1908). Portanto, a inclusão dessas penalidades no regulamento não causa surpresa, pois estão em consonância com o que era então repetido nos periódicos médicos.

No que se refere à assepsia, em particular, deve ser mencionado que o destaque dado pela Lei 1134 (SAO PAULO, 1908) reflete a preocupação e a adesão dos médicos, pelo menos em nível de discurso, à teoria

Essa determinação foi revogada na Reorganização do Serviço Sanitário em 1911, pelo Decreto 2141 (SÃO PAULO, 1911). As parteiras práticas habilitadas pela Escola Livre de Farmácia foram novamente autorizadas a exercer a profissão. Na reforma do Serviço Sanitário de 1917 (Lei 1596), ao lado dos diplomas conferidos e habilitados pela ELFOO, incluiu-se o da Escola de Parteira\& de São Paulo (SAO PAULO, 1917), 
bacteriana da transmissão das doenças, como também, o quanto eles estavam sintonizados com o que estava sendo dito em outros países, visto a imagem da parteira leiga como transmissora de doenças ser, então, encontrada com freqüência na literatura médica européia e norte-americana. Quanto a ser um reflexo do que ocorria na prática, pode-se ter algumas dúvidas. Vale lembrar que nem os partos feitos por médicos nas residências, nem nas maternidades eram seguros. As autoras do livro The Midwife's Tale (LEAP e HUNTER, 1993) referem-se ao mesmo tipo de acusação feita às parteiras leigas inglesas. As autoras afirmam que tradicionalmente as antigas comadres além de partejar, eram chamadas para lavar e vestir os mortos e possuíam rituais de lavagem das mãos, antes mesmo que a teoria sobre transmissão de infeções fosse entendida. Quando os médicos passaram a fazer os partos eles não tinham incorporado a prática da lavagem das mãos e a mortalidade por febre puerperal era brutal. Vários hospitais foram fechados para desinfeção e mães e crianças foram enviadas de volta para suas casas. Em São Paulo, a situação não era diferente. Apesar das parteiras serem acusadas como principais responsáveis pela transmissão de infeção, em 1900, as mulheres grávidas acolhidas pela Maternidade de São Paulo foram reenviadas para seus domicílios devido a existência de vários casos de febre puerperal na enfermaria da entidade que, na época, era sediada na Ladeira Santa Efigênia (PASSOS, 1960/

\section{1).}

Além das leis estaduais, as parteiras em São Paulo também se depararam com restrições do poder municipal. No século XIX, conforme atestam memorialistas, viajantes estrangeiros era usual a parteira tradicional anunciar a profissão através de uma cruz branca na porta das casas. Outras, tinham placa com o nome e a profissão (MOTT, 1998).

Em São Paulo na virada do século, a profissão era anunciada através de tabuletas com desenhos alegóricos à profissão, sendo que algumas delas estampavam crianças recémnascidas nuas. Em 1902, o vereador Evaristo da Veiga mandou ao Dr. Antônio Prado, então prefeito da cidade, uma indicação pedindo que fossem proibidas tais tabuletas, devendo ser substituídas por placas indicativas do nome e a profissão. A razão alegada era de que havia no Código de Posturas um artigo, proibindo e punindo a colocação de quadros e figuras ofensivas à moral pública. O engenheiro fiscal da Viação, João J. Vaz de Oliveira, encarregado de fazer a verificação, concordou com o vereador afirmando que eram "patentes os inconvenientes que muitas dessas tabuletas ofereciam à moral com a figuras nuas de recém-nascidos" e recomendava que fosse expedido um edital obrigando as parteiras, num prazo de 30 dias, habilitarem junto à Prefeitura, os desenhos e os dizeres das tabuletas. O diretor da Polícia administrativa, Sr. Alberto Costa, ponderou que ao invés do edital, os fiscais deveriam avisar as parteiras para substituírem as tabuletas com figuras, por letreiros simples, indicando o nome e a profissão e submeter à aprovação da Prefeitura, conforme a Lei 226. Um mês e meio depois, o diretor da Polícia Administrativa apresentou uma relação com o endereço das parteiras cujas tabuletas não deveriam ser permitidas, e somavam 14 no total... (SANT 'ANA, 1939)

Não foi possivel verificar se a polícia administrativa municipal foi eficiente e retirou as tabuletas na ocasião. Pode-se dizer porém que a fiscalização do exercício profissional das parteiras sem diploma pelas autoridades do Serviço Sanitário não foi cumprida com rigor nas primeiras décadas do século.

As parteiras práticas continuaram a exercer a profissão, amparadas pelas parturientes, pelos médicos e até mesmo pela Justiça. Em maio de 1915, os Anais Paulistas de Medicina e Cirurgia, publicou um parecer médico-legal do Dr. Vieira Marcondes, médico da Maternidade São Paulo e professor da Escola de Parteiras, no qual criticava uma decisão do Supremo Tribunal de São Paulo, que absolvera em 08 de fevereiro daquele ano, "uma parteira curiosa", causadora da morte de um feto. O argumento utilizado pelo juiz para a absolvição, baseava-se no fato que a denunciada não exercia a medicina profissionalmente tratava-se de uma senhora que costumava prestar os serviços de parteira a quem pedisse e nada cobrava por isso, portanto nem vivia, nem tirava o sustento da especialidade.

O médico refuta dizendo que a caridade ou a falta de pagamento pelo serviço da aparadeira, não poderiam, nem deveriam, inocentá-la pois existia uma lei que punia o exercício ilegal da profissão e os atos que praticava, sempre expunham mãe e filho a perigos. Para ele, as aparadeiras eram elementos perniciosos na sociedade, pois usavam medicamentos de forma inadequada, provocavam infeção pelo excesso de toque, não tinham noções básicas de obstetricia que permitissem reconhecer determinados problemas durante a gestação, o parto e o puerpério, e recorrer, a tempo, ao médico. Era indispensável que aquelas que extrapolassem suas atribuições fossem fiscalizadas e punidas pelos poderes competentes. Não era porém contra as parteiras diplomadas. Defende a parteira habilitada, com instrução teórica e experiência adquirida na prática hospitalar, e atribui a essas profissionais um papel profilático, seja durante a gestação, como durante o parto e o puerpério. Reconhece que a fiscalização e a punição das parteiras pelos poderes competentes era muito dificil e argumenta que em geral, os próprios médicos não as denunciavam, ou por não tomarem "a pecha" de delatores, ou por benevolência (MARCONDES, 1915 
Outras questões talvez devessem ser consideradas sobre a razão da dificuldade de se fiscalizar e punir as parteiras. $O$ parto e o atendimento ginecológico feito por médicos não era uma unanimidade na sociedade brasileira da época (MOTT, no prelo). Embora sejam freqüentes as denúncias por parte da classe médica da imperícia das comadres e delas continuarem a fazer atendimento ginecológico, alguns autores deixam evidente que não só as parteiras eram preferidas por muitas familias, como atuavam em conjunto com os próprios médicos. Reclama o Dr. AZEVEDO JR. (1908), no artigo Das Comadres no Rio de Janeiro, publicado na Revista de Ginecologia e d'Obstetricia: "Todas se declaram protegidas por esse ou por aquele médico e a gente pasma, quando ouve os nomes de colega, acima de toda a suspeita, como protetores de tais mulheres". Se tomarmos ao pé da letra uma frase do artigo poderíamos acrescentar que no Brasil, nem mesmo entre os médicos, a presença desse profissional era vista como necessária no parto. Lê-se no artigo da revista acima citada: "em geral os médicos que não se ocupam de partos, acham que em se tratando de ato fisiológico, normal, toda pessoa serve e argumentam dizendo que os animais não precisam de parteiros.

A observação feita pela historiadora TUCAT (1981) sobre a fiscalização das parteiras francesas na virada do século parece válida para São Paulo no mesmo período. Segundo a autora, apesar das parteiras estarem proibidas de tratar doenças de mulheres, a maioria praticava abertamente a ginecologia. Porém raramente eram perseguidas e punidas. A ausência de sanções, acredita Tucat, devia-se ao fato dos magistrados franceses acharem natural que as mulheres fossem tratadas por mulheres e não por um profissional do sexo masculino.

\section{Os cursos para formação de parteiras}

Qual então o papel, o lugar das parteiras na sociedade paulista nas primeiras décadas do século? Como se viu, a legislação restringiu seu papel ao parto normal, reforçou sua posição subalterna aos médicos, bem como limitou sua atuação, colocando-as sob maior supervisão, quando proibiu que recebessem parturientes pensionistas. Embora fossem freqüentemente criticadas por uma parcela da classe médica, eram vistas como necessárias, devendo por isso passar por um aprendizado feito numa escola sob supervisão de médicos.

A primeira escola para formação de parteiras em São Paulo, conforme acima mencionado, foi fundada em 1902 na Escola Livre de Farmácia. O curso era de dois anos, no primeiro ensinava-se Anatomia Descritiva e Médico Cirúrgica da bacia e dos órgãos genito-urinários da mulher, Noções de Embriologia e Obstetrícia; no segundo ano Clínica Obstétrica, Noções de Ginecologia e Terapêutica Obstétrica (ESCOLA DE FARMÁCIA ODONTOLOGIA E OBSTETRÍCA, 1903). Na lista geral dos alunos que concluíram, verifica-se que o curso de Obstetrícia em 10 anos de funcionamento, conferiu 17 diplomas de parteiras. O curso foi extinto em 1911, tendo funcionado porém uma classe de segundo ano, em 1912, quando se formaram nove parteiras, entre elas Maria da Glória Pinto da Silva, que fez o curso de Odontologia na mesma escola. ${ }^{4}$

Muito pouco foi possivel levantar sobre o curso e sobre as alunas ${ }^{5}$. O fato de ter sido extinto e pertencer a uma entidade que agregava mais duas escolas, que se tornaram posteriormente independentes, resultou na divisão dos documentos, dificultando consequentemente a pesquisa, visto que não existe um único responsável pelo acervo histórico, que segundo consta, era bastante rico. A Faculdade de Odontologia de USP, que guarda uma parte dele, possui uma lista da documentação existente no arquivo em 1942, na qual estão relacionados entre outros documentos, 56 prontuários de alunas do curso de Obstetrícia, que até o momento não foi possivel localizar.

Assim, várias questões sobre a escola ficaram sem resposta, como por exemplo qual a razão da extinção do curso? Pode-se excluir do rol de hipóteses, a falta de alunas ou a pequena importância atribuída à instrução das parteiras. No início de 1912, o mesmo Dr. Sílvio Maia, professor da antiga escola, fundou um novo curso de parteiras, anexo à Maternidade São Paulo, instituição da qual era diretor clínico ${ }^{6}$.

Ver Livro n.239, acima citado. Arquivo da Faculdade de Odontologia da USE

5 Até onde se sabe, o curso da ELFOO teria sído extinto em 1912. Porém, pela documentação levantada, pode-se afirmar que voltou a funcionar nos anos 30, visto terem sido levantados prontuários de alunas da referida escola, pedindo revalidação na Escola de Parteiras da Clínica Obstétrica da Faculdade de Medicina (Ver prontuário de Christina dePaula Agosto, "Alunas Matriculadas na Escola de Parteiras, 1912-1970"). Arquivo da Escola de Enfermagem da USE

6 A análise do início do Curso de Parteíras da Maternidade de São Paulo apresenta uma série de dificuldades. A documentação sugere que Silvio Maia, que também era professor na ELFOO, fundou a nova escola na Maternidade, tendo em vista a Clinica Obstétrica da Faculdade de Medicina, que estava para ser criada em São Paulo. Assim não só as alunas do curso de parteiras poderiam ter acesso a uma enfermaria obstétrica, como também os alunos do curso de Medicina. PASSOS (1960/61) afirma que inicialmente a Escola de Parteiras pertencia, de fato, à Maternidade. A partir de 1917, porém, a administração teria passado para as mãos da Clínica Obstétrica da Faculdade de Medicina, funcionando numa enfermaria própria, alugada pela Maternidade, Portanto a Maternidade e a Clínica Obstétrica tinham enfermarias independentes. 
$\mathrm{Na}$ reunião de fundação e instalação da Escola de Parteiras da Maternidade de São Paulo, realizada no dia 15/3/1912 Dr. Sílvio Maia justificou sua proposta, alegando que: 1) na cidade não havia uma escola semelhante, desde a extinção do curso de Obstetrícia da Escola de Farmácia; 2) havia falta de profissionais capacitadas para acompanhar "criteriosamente" o trabalho de parto, não só no interior como na capital; 3) a Maternidade vinha sendo procurada com freqüência por mulheres interessadas em obter formação de parteira e habilitação para o exercício da profissão, como para legalizar diploma; 4) a Maternidade se achava aparelhada para esse fim sem ter maiores encargos, além de estar realizando uma média de 60 partos mensais, muitos deles de interesse científico, o que possibilitaria um bom aprendizado para as alunas; e 5) que a idéia tinha sido bem recebida pela diretoria da instituição ${ }^{7}$.

O curso era de dois anos, tendo três cadeiras em cada ano. Comparando-se o curso extinto e o novo, verifica-se que no da Maternidade São Paulo as alunas tinham uma formação que incluía mais matérias, e uma maior prática em clínica, não apenas na Obstétrica, como na Ginecológica, além de cuidados com a criança. No primeiro ano, as alunas tinham aulas de Anatomia e Fisiologia da bacia e dos órgãos genito-urinário da mulher; Noções de Histologia, Microbiologia e Noções de Análises Clínicas; e Obstetrícia com prática de manobras em manequim. No segundo ano, tinham aulas de Clínica Obstétrica; Clínica Ginecológica; Puericultura, Patologia e Terapêutica do recém-nascido.

Em 1915, Silvio Maia enviou ao Legislativo Estadual um memorial no sentido de obter a legalização do curso, que até então vinha funcionando sem reconhecimento oficial, Explica o diretor que os professores do curso, sem exceção, eram especialistas em Obstetrícia, que o programa do curso seguia "os moldes mais modernos de ensino" e que as matérias, quer as básicas como as específicas à Tocologia, eram "lecionadas com desvelo e dedicação para infundir no espírito das futuras parteiras a importância de um sólido conhecimento da complexa e nobilíssima arte obstétrica Afirma que a inclusão das cadeiras de Clínica Ginecológica e Puericultura Patológica e Terapêutica do recém-nascido, obedecia "à elevada intelectuais mais adiantados, tornaram-se uma complementação indispensável ao estudo da Obstetrícia. Segundo o médico o programa de admissão ao primeiro ano tinha elaborado de modo que a "candidata demonstrasse conhecimentos imprescindiveis à inteligência perfeita da Obstetrícia". Eram exigidos exames de: Português, uma lingua estrangeira (Francês, Inglês, Alemão, Italiano), noções de Anatomia e Fisiologia Humana e Higiene.

Através do Regulamento da Escola de Parteiras de 1915 verifica-se que a idade minima exigida da candidata, na época da matrícula, era de 18 anos. Além de exame de admissão e pagamento da taxa exigia-se atestado de boa conduta e de não sofrer moléstias infecto-contagiosas e atestado de vacina contra a variola. Eram isentas do exame de admissão as candidatas que tivessem prestado exames finais nos ginásios oficiais ou equiparados e escolas normais.

O regime do curso não era de internato. Havia aulas três vezes por semana e tinha um preço que pode ser considerado era alto: a taxa de exame de admissão 10\$000, a taxa de exame de cada série, 50\$000; mensalidade por cadeira, 10\$000; o diploma de parteira, 200\$000; a taxa de revalidação de diploma de parteira estrangeira ,500\$000 ${ }^{8}$. O salário de uma parteira-chefe (14 parteira) na Maternidade São Paulo, em 10/10/1913 era de $150 \$ 000$ mensais, mais comida, casa e roupa lavada, e os dois anos de curso saia cerca de $1.000 \$ 000$ (um conto de réis) ${ }^{9}$.

O perfil das alunas das primeiras turmas, aponta para um grande número de casadas, viúvas e mulheres com filhos, inclusive uma mulher grávida, que deu à luz durante o curso. Nos primeiros anos de funcionamento, o corpo discente era composto sobretudo de mulheres de origem estrangeira, a maioria de italiana, com idade entre 30 e 40 anos. A partir da década de 20, houve uma mudança de perfil: as alunas eram moças mais jovens, um maior número de brasileiras, muitas delas vindas do interior do estado e com melhor escolarização, egressas de curso ginasial, normal, de Farmácia e de outras escolas de parteiras ou já trabalhando como enfermeiras. Vale destacar que algumas das alunas, tanto casadas como solteiras, sendo moradoras do interior, deixavam a família e vinham fazer o curso na Capital, o que

orientação científica" sendo que nos centros

\footnotetext{
Essas informações e a dos dois parágrafos seguintes foram obtidas no "Livro de Atas da Escola de Parteiras da Maternidade de São Paulo-1912-1970" (Ver Ata do día 13/11/1915). Arquivo da Escola de Enfermagem da USP.

8 Regulamento da Escola de Parteiras de São Paulo Reconhecido pela Lei Estadual n,1472, de 30/10/1915. Arquivo da Escola de Enfermagem da USE

9 Atas da diretoria 1894-1942" (Ver Ata do dia 10/10/1913). Arquivo Maternidade de São Paulo.
} 
sugere, entre outras coisas, a importância atribuída à formação, a compensação monetária que se esperava com a obtenção do diploma, e, sobretudo, a determinação dessas mulheres'

Pode-se afirmar que o curso era totalmente subordinado ao saber médico e as profissionais ai formadas podiam trabalhar em conjunto com um médico, em maternidades e hospitais, como ainda por conta própria, como profissionais liberais.

O tipo de formação oferecido pela Escola de Parteiras da Maternidade de São Paulo não era a única preconizada no período, nem a seguida por todas as escolas. Na mesma época, alguns hospitais criaram cursos práticos de "parteiras-enfermeiras", voltados para formação de pessoal para trabalhar em hospitais e dispensários ou em casas de família. Em 1912, a Santa Casa de Misericórdia de Santos fundou uma Escola de Enfermeiros e Parteiras, que logo na primeira turma teve 72 alunos inscritos, sendo que 42 já trabalhavam no serviço clínico hospitalar. O projeto foi elaborado pelo Dr. Amancio da Cunha Motta. O ensino era eminentemente prático e tinha duração de dois anos. O primeiro ano era dividido em cadeiras básicas, onde se ensinava inclusive português e aritmética. No segundo ano, as matérias eram voltadas para enfermagem geral e de urgência (Noções de Patologia, de Bacteriologia, Terapêutica, Cirurgia de Urgência). Para quem quisesse ser parteira, o curso fornecia uma complementação, sendo que a prática da cadeira de Obstetrícia era ensinada nas clínicas oficiais do hospital da Santa Casa (NOTAS E INFORMAÇÕES, 1913).

A documentação sugere que na virada do século, já se podia perceber que a associação entre parteiras e enfermeiras torna-se mais freqüente, não ocorrendo apenas em alguns cursos para formação profissional, como no acima mencionado, mas também no cotidiano de trabalho. Passara a existir a expectativa de que a parteira fosse também enfermeira. Na hospedaria dos Imigrantes, em São Paulo, por exemplo, havia o cargo de "parteira-enfermeira", que aliás foi extinto em 1899, quando o serviço de partos ficou a cargo do médico e foi criado o cargo de enfermeira. Outro sinal dos novos tempos: as parteiras pouco a pouco viram suas antigas atribuições apropriadas, em parte, pelo exercício da Obstetrícia pelos médicos, em parte, pelas enfermeiras, devido entre outras razões, à crescente importância da Medicina Preventiva e às modificações e ampliações dos serviços de saúde, tais como a criação de hospitais, maternidades e centros de saúde.
Apesar desses sinais de mudança a parteira leiga ainda mantinha primazia no atendimento ao parto. Dr. Edgard Braga , que na década de 30 foi chefe do Serviço de Pré-Natal da Inspetoria de Higiene e Assistência à Infância em São Paulo, verificou a partir de pesquisa feita em 18 mil fichas de gestantes atendidas pela instituição no decorrer de oito anos, que $85 \%$ foram atendidas por curiosas, $10 \%$ por parteiras diplomadas e 5\% em hospitais e maternidades (BRAGA, 1937).

Em 1971, a Escola de Obstetrícia da Clínica Obstétrica da Faculdade de Medicina da USP, como então era nomeada a antiga Escola de Parteiras da Maternidade de São Paulo, foi incorporada à Faculdade de Enfermagem da USP, medida que na época causou reações diversas, entre elas de revolta por parte de muitas obstetrizes. Será que a partir da história da formação e da fiscalização de parteiras em São Paulo, aqui apresentada, não seria possível levantar-se a hipótese que esse destino começou a ser delineado desde as primeiras décadas do século XX?

\section{REFERÊNCIAS BIBLIOGRÁFICAS}

AZEVEDO JR. Das comadres no Rio de Janeiro. Rev Ginecol Obstet, v.1, n,1-2, p.279-81,1908.

BRAGA, E. Da assistência ao parto nas maternidades. Rev Ginecol Obstet, v.31, v.5, p.289-92, 1937.

BRASIL. Decreto 1371, de 28 de agosto de 1905. Equipara às Escolas Oficiais as Escolas de Farmácia, Odontologia e Obstetrícia de São Paulo. Coleção de Leis da República Federativa do Brasil, 1905,

BRASIL. Decreto 169, de 18 de janeiro de 1890. Constitui o Conselho de Saúde Pública e reorganiza o Serviço Sanitário Terrestre da República. Coleção de Leis do Governo Provisório, 1890.

BRASIL. Decreto 2548, de 10 de fevereiro de 1897. Aprova o Regulamento da Diretoria Geral de Saúde Pública e a tabela de vencimentos do respectivo pessoal. Coleção de Leis da República Federativa do Brasil, 1897.

BRASIL. Decreto 666, de 14 de novembro de 1891. Declara desligada da Administração Federal a Inspetoria de Higiene de São Paulo. Coleção de Leis da República, 1891.

BRASIL. Decreto 9554, de 03 de fevereiro de 1886. Reorganiza o Serviço Sanitário do Império. Coleção de Leis do Império, 1886. 
ESCOLA DE FARMÁCIA, ODONTOLOGIA E OBSTETRÍCIA DE SÃO PAUlO. Administração, Corpo Docente e Alunos. São Paulo, Tip. Salesiana, 1903,

ESCOLA Livre de Farmácia. Rev Méd São Paulo, v.3, n.5, p.109-10, 1900.

EXERCÍCIO Ilegal da Medicina. Rev Méd São Paulo, v.1, n.7, p. $121,1898$.

LEAP, N,; HUNTER, B. The midwife's tale. London, Scarlet Press, 1993.

MARQUES, A.A.S, Indicador de São Paulo: 1878. São Paulo, DASP/IMESP, 1983.

MOTT, M.L. Parto, parteiras e parturientes no século XIX: Mme. Durocher e sua época. São Paulo, 1998, 331p,Tese (Doutorado) - Faculdade de Filosofia, Letras e Ciências Humanas, Universidade de São Paulo.

MOTT, ML, Assistência ao parto: do domicílio ao hospital (18301960). Rev Est Feministas (no prelo).

NOTAS e Informações. Escola de Enfermeiros e Parteiras. Rev Méd São Paulo, v,21, n.2, p.163-4, 1913.

NOTÍCIAS. Rev Méd São Paulo, v.9, n.23, p.475, 1906.

SERVIÇO Sanitátio. O Estado de São Paulo, São Paulo, 17 fev. 1899.

PARTEIRAS. Estado de São Paulo, Sao Paulo, 24 abr. 1896.

PASSOS, EM. A maternidade de São Paulo na obstetrícia paulista. Anais Matern São Paulo, v.6, p.17-96, 1960/61.

SANT'ANA, N. São Paulo histórico: aspectos, lendas e costumes. São Paulo, Departamento de Cultura, 1939. v,3.

SÃO PAULO (Estado), Decreto n.2141 de 28 de outubro de 1911. Reorganiza o Serviço Sanitário do Estado. Coleção de Leis do Estado de São Paulo, 1911.

SÃO PAULO (Estado). Lei n.1596 de 29 de dezembro de 1917, Reorganiza o Serviço Sanitário do Estado. Coleção cite Leis do Estado de São Paulo, 1917,

SÃO PAULO (Estado). Lei n.1134, de 07 de outubro de 1908. Regula o exercício das profissões de farmacêutico, dentista e parteira. Coleção de Leis do Estado de São Paulo, 1908.

SÃO PAULO (Estado). Lei n.240, de 04 de setembro de 1893, Reorganiza o Serviço Sanitário do Estado. Coleção de Leis do Estado de São Paulo, 1893.

SÃO PAULO (Estado). Lei n.394, de 07 de outubro de 1896. Aprova o Regulamento do Serviço Sanitário. Coleção de Leis do Estado de São Paulo, 1896.

SÃO PAULO (Estado), Lei n.43, de 18 de julho de 1892. Organiza o Serviço Sanitário do Estado. Coleção de Leis do Estado de São Paulo, 1892.

SÃO PAULO (Estado). Lei n.665, de 06 de setembro de 1899; Decreto n.780, 28/05/1900. Coleção de Leis do Estado de São Paulo, 1899.
SÃO PAULO (Estado). Lei n.897, de 30 de novembro de 1903. Díspõe sobre a Escola Livre de Farmácia, Coleção de Leis do Estado de São Paulo, 1903,

TUCAT, D, Les sages-femmes parisiennes à la fin du XIX siècle. PENEPOLE pour l'histoire des femmes, n.5, p.58-61, 1981.

\section{BIBLIOGRAFIA CONSULTADA}

BEAUVALET-BOUTOUYRIE, Scarlet. Naitre à 1'hôpital au XIXe siècle. Paris, Belin, 1999

JORGE, Dilce Rizzo, Evolução da legislação federal do ensino e do exercicio profissional da obstetriz. São Paulo, 1975. 21.3p. Tese (Livre Docência) - Escola de Enfermagem Anna Nery, Universidade Federal do Rio de Janeiro.

MARCONDES, Vieira. Responsabilidade criminal das aparadeiras ou curiosas. Anais Paul.Med.Cir.: v.3, n.5, p.1014, 1915.

MASCARENHAS, Rodolfo dos Santos. Contribuição para o estudo da administração sanitária estadual em são Paulo. São Paulo, 1949. 565p,Tese (Livre Docência) - Faculdade de Higiene e Saúde Pública, Universidade de São Paulo.

MORAES, Arnaldo. Do exercício da profissão de parteira. Rev. Ginecol.Obstet., v.17, n.2, p.45-50, 1923.

OSAVA, Ruth Hitomi. Assistência ao parto no Brasil: o lugar do não médico. São Paulo, 1997. 129p. Tese (Doutorado)- Faculdade de Saúde Pública, Universidade de São Paulo.

POURCHET-CAMPOS, Maria Aparecida. A vida da Faculdade de Ciências Farmacêuticas da USP: notas históricas. São Paulo, FCFUSP, 1984.

RIBEIRO, Maria Alice Rosa. História sem fim... Inventário da Saúde Pública em São Paulo (1880-1930). São Paulo, UNESP, 1993.

RIESCO, Maria Luiza Gonzalez. Que parteira é essa? São Paulo, 1999. 193p.Tese (Doutorado) - Escola de Enfermagem, Universidade de São Paulo.

TSUNECHIRO, Maria Alice. Formação da enfermeira obstétrica no estado de São Paulo. São Paulo, 1987. 108p. Tese (Doutorado) - Escola de Enfermagem, Universidade de São Paulo.

WEBER, Beatriz Teixeira Weber. As artes de curar: medicina, religião, magia e positivismo na República RioGrandense (1889-1928). Santa Maria, UFSM/EDUSC, 1999.

Artigo recebido em 10/09/99

Artigo aprovado em 11/07/01 